\title{
ESTIMATIVA DO BALANÇO DE ENERGIA EM CAMBARAZAL E PASTAGEM NO NORTE DO PANTANAL PELO MÉTODO DA RAZÃO DE BOWEN
}

\author{
MARCELO SACARDI BIUDES, JOSÉ HOLANDA CAMPELO JÚNIOR, \\ JOSÉ DE SOUZA NOGUEIRA E LUCIANA SANCHES
}

\author{
Universidade Federal de Mato Grosso - (UFMT) Cuiabá - MT, Brasil
}

marcelo@pgfa.ufmt.br, campelo@ufmt.br, nogueira@ufmt.br, lsanches@ufmt.br

Recebido Março 2008 - Aceito Março 2009

\begin{abstract}
RESUMO
O estudo do balanço de energia de uma superfície vegetada e a atmosfera é importante para caracterizar o microclima local, identificar interações entre variáveis ambientais e a vegetação, e identificar efeitos das atividades antropogênicas. O objetivo deste trabalho foi estimar a variação sazonal do balanço de energia pelo método da razão de Bowen em uma área de vegetação monodominante de Cambará na RPPN SESC-Pantanal e uma área de pastagem na Fazenda Experimental da UFMT. Os componentes do balanço de energia apresentaram sazonalidade, com maiores médias na estação chuvosa nas duas áreas de estudo. No cambarazal houve maior variação do fluxo de calor latente da estação seca para a chuvosa que na pastagem. Entretanto, a variação sazonal do fluxo de calor sensível foi menor no cambarazal que na pastagem, devido ao efeito termo-regulador do cambarazal, em função da maior biomassa. A energia disponível aos dois sítios foi destinada prioritariamente em fluxo de calor latente, $80,0 \%$ no cambarazal e $56,6 \%$ na pastagem, seguido pelo fluxo de calor sensível, 19,1 e $42,9 \%$, e pelo fluxo de calor no solo, 0,3 e 7,2\%.
\end{abstract}

Palavras-chave: razão de Bowen; sazonalidade; floresta tropical; microclima.

\begin{abstract}
ESTIMATE OF ENERGY BALANCE IN CAMBARAZALAND PASTURE IN THE NORTH OF PANTANAL BY BOWEN RATIO METHOD.

The energy balance study of a vegetated surface and atmosphere is important to characterize the local microclimate, identify interactions among environmental variables and the vegetation and to identify anthropogenic activities effects. The objective of this work was estimate the seasonality of energy balance by Bowen ratio method in a monodominant vegetation of Cambará area in the RPPN SESC-Pantanal and a pasture area in UFMT's Experimental Farm. The energy balance components presented seasonality, with larger averages at the rainy station in two areas of study. In the cambarazal was a higher variation of the latent heat flux of the dry season for the rainy season that in the pasture. However, the seasonal variation of the sensible heat flux in the cambarazal was lower than in the pasture, due to the thermo-regulatory effect in the cambarazal, according to the largest biomass. The available energy at two ranches was partitioned priority in latent heat flux, $80,0 \%$ in the cambarazal and $56,6 \%$ in the pasture, followed by the sensible heat flux, 19,1 and $42,9 \%$, and by the soil heat flux, 0,3 and $7,2 \%$.
\end{abstract}

Keywords: Bowen ratio; seasonality; tropical forest; microclimate.

\section{INTRODUÇÃO}

O estudo em florestas tropicais ganhou atenção especial, principalmente, pela riqueza de fauna e flora. O Pantanal apresenta características distintas dos outros biomas por ser caracterizado como a maior planície inundada da América do Sul, e ser um elo entre os biomas vizinhos como a Amazônia, o Cerrado e os Chacos Boliviano e Paraguaio, apresentando prolongamentos naturais na área circunvizinha.

O pulso de inundação do Pantanal é a principal força moderadora, levando à livre formação de estandes monodominantes devido à sua baixa drenagem e ao freqüente prolongamento do período de inundação. Outra característica é a ocorrência de uma estação seca (entre abril e setembro), que 
causa freqüente estresse hídrico nas plantas locais, regulando sua fenologia e produção de fitomassa (Junk, 2002).

Entre as espécies que se espalham a cada pulso de inundação, o cambará (Vochysia divergens) se destaca por apresentar características ecológicas e fisiológicas, que favorecem ser rápido espalhamento e dominância em campos sazonalmente inundados. Sua alta taxa de crescimento sob intensa luminosidade, tolerância à condição de prolongado alagamento, capacidade de suas plântulas em manter suas folhas intactas embaixo da superfície da água e elevada produção de sementes espalhadas pelo vento e água são algumas delas (Nunes da Cunha e Junk, 2004).

Nas últimas décadas, vêm crescendo incentivos políticos e sociais para o aumento da atividade econômica na região pantaneira, antes realizada de forma extrativista. Isso tem intensificado o uso de pastagem para a criação de bovinos, seja por forrageiras naturais ou exóticas (Santos e Costa, 2002).

$\mathrm{O}$ aumento do desmatamento para a criação de gado pode modificar o clima local, levando as sérias conseqüências ecológicas, como o aumento da temperatura do ar, redução na precipitação e evaporação e o prolongamento da estação seca (Nobre et al., 1996).

Estudos de trocas de energia entre a superfície e a atmosfera são importantes, não só para caracterizar o microclima local, como identificar interações existentes entre elas. Além disso, possibilita conhecer variações do tempo e do clima da região, assim como, pode auxiliar na identificação de efeitos de atividades antropogênicas, como o desmatamento e queimadas, ou fatores naturais, sobre diferentes questões ambientais da região. Esse tipo de estudo é fundamental por fornecer informações sobre a quantidade de umidade transferida para atmosfera por uma área de vegetada, seja por uma vegetação rasteira ou de médio porte (Oliveira et al., 2006).

Neste contexto, algumas técnicas micrometeorológicas vêm sendo usadas para estimar as trocas de energia em uma superfície vegetada, sem a alteração do meio. O método da razão de Bowen pode estimar a partição da energia disponível em fluxos de calor latente e sensível por meio de medidas realizadas diretamente no campo, como o saldo de radiação e o fluxo de calor no solo, e estimativas dos gradientes de temperatura e pressão de vapor d'água (Pezzopane e Pedro Júnior, 2003).

O método da razão de Bowen, apesar de incluir em seus pressupostos o fechamento do balanço de energia, tem sido utilizado como método padrão em cultivos anuais (Lima et al., 2005), por apresentar baixo custo e facilidade de instalação do experimento. Em floresta, as estimativas dos fluxos de calor latente e sensível por esta técnica tem concordado com valores obtidos pelo método de correlação de vórtices turbulentos (Arruda et al., 2006), e em pastagem, com medidas lisimétricas (Silva et al., 2005).
Apesar do amplo emprego do método da razão de Bowen, alguns autores têm relatado limitações em seu uso. Um ponto vulnerável é quando o valor da razão de Bowen se aproxima de $-1,0$, apresentando fluxos com magnitudes extremamente inadequadas, pois os erros nas estimativas apresentam magnitudes semelhantes às estimativas dos fluxos (Liu e Foken, 2001). Ortega Farias et al. (1996) recomendam descartar valores inferiores à $-0,75$ durante o nascer e por do sol e durante a noite, devido à dificuldade de estimar gradientes de temperatura e pressão de vapor d'água. Jarvis et al. (1976) observaram a necessidade do estabelecimento de uma faixa de utilização em floresta de coníferas, argumentando serem entre 0,1 a 1,5 em condições secas e - 0,7 a 0,4 em condições úmidas.

Visto a falta de informação sobre o balanço de energia em área de floresta e pastagem na região do Pantanal, o objetivo deste trabalho foi estimar a variação sazonal do balanço de energia pelo método da razão de Bowen, em uma área de vegetação monodominante de Cambará na RPPN SESC-Pantanal e em uma área de pastagem na Fazenda Experimental da UFMT.

\section{MATERIAL E MÉTODOS}

\subsection{Localização das Áreas Experimentais}

O experimento foi conduzido em duas áreas experimentais que apresentam características climáticas similares, com uma estação seca entre abril e setembro e uma chuvosa entre outubro e março. Uma área estava localizada na Reserva Particular do Patrimônio Natural - RPPN SESC - Pantanal, município de Barão de Melgaço - MT, distante 160 km de Cuiabá - MT em que estava instalada uma torre micrometeorológica de $32 \mathrm{~m}$ de altura (16³9'50'S; 5647'50”O) e altitude de $120 \mathrm{~m}$. Esta área apresenta vegetação monodominante de Cambará (Vochysia divergens), conhecido localmente como cambarazal, com altura do dossel variando entre 28 a $30 \mathrm{~m}$. O solo foi classificado como GLEISSOLO HÁPLICO Ta Distrófico.

A segunda área experimental foi uma pastagem mista localizada na Fazenda Experimental da Universidade Federal de Mato Grosso (1547'11's; 5604'47’O), e altitude de 140 $\mathrm{m}$, situada no município de Santo Antônio do Leverger - MT, distante $33 \mathrm{~km}$ de Cuiabá - MT. Esta pastagem mista é composta de duas espécies de forrageiras, capim carona (Elyonurus muticus) e Brachiaria humidicola. O solo foi classificado como PLANOSSOLO HÁPLICO Eutrófico gleissólico.

\subsection{Instrumentação Utilizada}

O saldo de radiação foi medido por meio de um saldo radiômetro (Net Radiometer, Kipp \& Zonen Delft, Inc., Holland), 
e a radiação solar incidente através de um piranômetro (LI-200, Campbell Sci, Inc., USA) a $33 \mathrm{~m}$ de altura no cambarazal e a $2,5 \mathrm{~m}$ na pastagem. $\mathrm{O}$ fluxo de calor no solo foi obtido por meio de dois fluxímetros de calor no solo no cambarazal (HFT-3.1, REBS, Inc., Seattle, Washington) e um fluxímetros de calor no solo na pastagem a $2 \mathrm{~cm}$ de profundidade. Os gradientes de temperatura e umidade do ar foram estimados por meio de dois termohigrômetros (HMP 45 C, Vaisala, Inc., Helsinki, Finland) instalados a 33,7 e 37,7 m no cambarazal e a 0,5 e 2,8 $\mathrm{m}$ na pastagem.

No cambarazal, os equipamentos foram alimentados com tensão de $12 \mathrm{~V}$ por duas baterias de $150 \mathrm{Ah}$, carregadas por um painel solar de $64 \mathrm{~W}$ com regulador de tensão, e na pastagem todos os equipamentos foram alimentados com tensão de $12 \mathrm{~V}$ por uma fonte $\mathrm{AC} / \mathrm{DC}$ de $10 \mathrm{~A}$, alimentada pela rede de corrente alternada de $127 \mathrm{~V}$ disposta no local.

Nas duas áreas os dados produzidos por sinais e pulsos elétricos dos transdutores foram processados e armazenados por um datalogger (CR 10X, Campbell Scientific, Inc., Ogden, Utah), com médias de 15 minutos. Para aumentar o número de canais de entrada do registrador foi utilizada uma placa multiplexadora (AM16/32A-ST-SW, Campbell Scientific, Inc., Ogden, Utah).

\subsection{Estimativa do Balanço de Energia pelo Método da Razão de Bowen}

O método da razão de Bowen foi utilizado para estimar os componentes do balanço de energia no cambarazal e na pastagem. A razão de Bowen é a razão dos fluxos de calor sensível $(H)$ e latente $(L)$, dado pela equação. (1), podendo ser re-escrita na equação (2)

$$
\begin{aligned}
& \beta=\frac{H}{E} \\
& \beta=\gamma \frac{\Delta T}{\Delta e}
\end{aligned}
$$

em que $\Delta T$ é diferença de temperatura do ar entre dois níveis $\left({ }^{\circ} \mathrm{C}\right), \Delta e$ é diferença de pressão de vapor d'água do ar entre dois níveis $(\mathrm{kPa})$ e é o constante psicrométrica $(0,0626$ $\left.\mathrm{kPa}^{\circ} \mathrm{C}-1\right)$.

A pressão de vapor d'água do ar saturado $\left(e_{5}\right)$ em $(\mathrm{kPa})$ para cada altura foi calculada como uma função da temperatura do $\operatorname{ar}\left(T_{\mathrm{a}}\right)$ em cada altura, conforme a equação (3).

$$
e_{s}=0,6108.10^{\left(\frac{7,5 T_{a}}{237,3+T_{a}}\right)}
$$

A pressão de vapor d'água do ar atual (e) foi calculada e a pressão de vapor d'água do ar saturado $\left(e_{\mathrm{S}}\right)$, conforme a equação (4).

$$
\begin{gathered}
e=e_{\mathrm{S}} \mathrm{UR}_{\mathrm{a}} \\
E=\frac{\mathrm{Rn}-G}{(1+\beta)}
\end{gathered}
$$

O fluxo de calor sensível $(H)$ em $\left(\mathrm{W} \mathrm{m}^{-2}\right)$ foi obtido pelo produto da razão de Bowen $(\beta)$ e o fluxo de calor latente $(L E)$.

Os termohigrômetros foram calibrados antes da instalação no local de estudo, colocando-os nas mesmas condições. Após dez dias de medida foi realizada uma regressão linear simples com os valores medidos de temperatura e pressão de vapor, tendo como referência o termo-higrômetro localizado a 33,7 $\mathrm{m}$ no cambarazal e a $0,5 \mathrm{~m}$ na pastagem.

A faixa de utilização da razão de Bowen foi de $-0,7$ e 1,5, segundo a recomendação de Jarvis et al. (1976). Os valores abaixo de $-0,7$ e acima de 1,5 m foram descartados, e para preenchimento dos valores descartados, foram realizadas regressões lineares simples entre os valores dos fluxos não descartados e do saldo de radiação obtidos três dias antes e três dias após serem observados valores de razão de Bowen fora da faixa utilizada.

\section{RESULTADOS E DISCUSSÃO}

\subsection{Variação sazonal dos componentes do balanço de energia}

O saldo de radiação $(R n)$ nas duas áreas de estudo apresentou padrão semelhante de variabilidade sazonal sazonalidade $(\mathrm{r}=0,85)$, as médias anuais nas duas áreas não diferiram entre si $(\mathrm{p}>0,05)$ e não houve efeito da área de estudo $(\mathrm{p}<0,05)$ O Rn médio mensal foi maior em março, 13,9 $\mathrm{MJ} \mathrm{m}^{-2} \mathrm{dia}^{-1}$ no cambarazal e $14,2 \mathrm{MJ} \mathrm{m}^{-2} \mathrm{dia}^{-1}$ na pastagem, enquanto que os menores valores foram $6,9 \mathrm{MJ} \mathrm{m}^{-2} \mathrm{dia}^{-1}$ no cambarazal (junho e julho) e na pastagem foi 7,3 $\mathrm{MJ} \mathrm{m}^{-2} \mathrm{dia}^{-1}$ em junho (Tabela 1).

O mês de setembro se destacou dos demais por apresentar menor média do Rn nos dois locais de estudo, o que pode estar relacionado com o início das queimadas na região, aumentando a quantidade de partículas na atmosfera. Por ser um mês que apresenta baixa disponibilidade de água no solo em função da baixa precipitação, os fazendeiros da região realizam queimadas de vegetação indesejada e desmatamento neste período (Nunes da Cunha e Junk, 2004). Nesta situação, a composição química 
da atmosfera sofre grandes mudanças devido às emissões de gases traço e partículas de aerossóis provenientes de queimadas de pastagem e desmatamento de floresta (Artaxo et al., 2002).

No cambarazal, houve aumento de $55,8 \%$ da média diária do Rn da estação seca para a chuvosa, e na pastagem esse acréscimo foi de 42,8\% (Tabela 1). O maior desvio padrão do Rn na estação chuvosa está relacionado à maior quantidade de nuvens neste período, e a menor média ocorrida na estação seca está relacionada com o fator astronômico, que reduz a radiação solar incidente até um valor mínimo em junho e um máximo em dezembro.

O fluxo de calor latente (LE) apresentou variação concordando com o $\mathrm{Rn}$ medido no cambarazal $(\mathrm{r}=0,99)$ e na pastagem $(r=0,90)$. A maior variação estacional do LE foi observada no cambarazal, com incremento de $60,6 \%$ da estação seca para a chuvosa, e na pastagem foi de $29,5 \%$ (Tabela 1 ). Trabalhos comparativos do balanço de energia em pastagens e em floresta demonstram que o LE apresenta menores valores em pastagem e, as maiores taxas de LE durante a estação chuvosa é reflexo da maior disponibilidade de água no solo em função da maior precipitação (Nobre et al., 1996; Galvão e Fisch, 2000; Priante Filho et al., 2004).

$\mathrm{Na}$ pastagem, houve incremento de $10,6 \%$ no LE de julho a agosto devido à instalação de um sistema de irrigação nos dias 26 e 27 de agosto. O incremento de $27,6 \%$ de julho a setembro foi devido ao rompimento da tubulação de fornecimento de água do sistema de irrigação, provocando o depósito da água na superfície (Tabela 1).

No cambarazal, a média estacional do LE na estação chuvosa (Tabela 1) esteve de acordo com valores encontrados em florestas tropicais úmidas (Shuttleworth, 1988; Roberts et al., 1993) e em floresta de transição Amazônia-Cerrado (9-10 MJ $\mathrm{m}^{-2}$ dia $^{-1}$ ) (Vourlitis et al., 2002; Priante Filho et al., 2004). Na estação seca, esteve próximo aos observados em floresta tropical úmida (6-8 $\mathrm{MJ} \mathrm{m}^{-2} \mathrm{dia}^{-1}$ ) (Shuttleworth, 1988; Roberts et al., 1993) e em floresta de transição Amazônia-Cerrado (6-10 MJ $\mathrm{m}^{-2} \mathrm{dia}^{-1}$ ) (Vourlitis et al., 2002; Priante Filho et al., 2004).

Na pastagem, a média estacional do LE foi menor (Tabela 1) que os encontrados em pastagens na região Amazônica, na estação chuvosa em Cotriguaçú, 7,9 $\mathrm{MJ} \mathrm{m}^{-2} \mathrm{dia}^{-1}$ (Priante Filho et al., 2004) e em Ji-Paraná, 7,2 $\mathrm{MJ} \mathrm{m}^{-2} \mathrm{dia}^{-1}$ (Galvão e Fisch, 2000) e na estação seca, 5,2 e $6,7 \mathrm{MJ} \mathrm{m}^{-2} \mathrm{dia}^{-1}$, respectivamente.

$\mathrm{O}$ fluxo de calor sensível $\mathrm{H}$ diário apresentou variação concordante com o $\mathrm{Rn}$ diário no cambarazal $(\mathrm{r}=0,86)$ e na pastagem $(r=0,85)$, sendo maior na estação chuvosa e menor na estação seca, influenciado pela variação da disponibilidade hídrica do solo (Tabela 1).

Tabela 1 - Média mensal e estacional e desvio padrão mensal e estacional do saldo de radiação (Rn), do fluxo de calor no solo (G), do fluxo de calor latente (LE) e do fluxo de calor sensível $(\mathrm{H})$ no cambarazal e na pastagem.

\begin{tabular}{|c|c|c|c|c|c|c|c|c|}
\hline \multirow[b]{2}{*}{$\begin{array}{c}\text { Mês' } \\
\text { Estação }\end{array}$} & \multicolumn{2}{|c|}{$R n\left(\mathrm{MJ} \mathrm{m}^{2} \mathrm{dia}^{2}\right)$} & \multicolumn{2}{|c|}{$G\left(\mathrm{MJ} \mathrm{m}^{-2} \mathrm{dia}^{-1}\right)$} & \multicolumn{2}{|c|}{$L E\left(\mathrm{MJ} \mathrm{m}^{-2} \mathrm{dia}^{-1}\right)$} & \multicolumn{2}{|c|}{$H\left(\mathrm{MJ} \mathrm{m}^{2} \mathrm{dia}^{2}\right)$} \\
\hline & Camb. & Past. & Camb. & Past. & Camb. & Past. & Camb. & Past. \\
\hline Jan & $13,2 \pm 3,8$ & & $0,1 \pm 0,1$ & & $10,9 \pm 3,1$ & & $2,3 \pm 0,7$ & \\
\hline $\mathrm{Fev}$ & $12,4 \pm 4,2$ & $12,2 \pm 3,6$ & $0,1 \pm 0,2$ & $0,0 \pm 0,3$ & $10,1 \pm 3,3$ & $6,0 \pm 1,7$ & $2,1 \pm 0,8$ & $6,2 \pm 1,7$ \\
\hline Mar & $13,9 \pm 3,5$ & $14,2 \pm 1,9$ & $0,1 \pm 0,2$ & $-0,1 \pm 0,2$ & $11,4 \pm 2,8$ & $7,2 \pm 1,0$ & $2,4 \pm 0,6$ & $7,1 \pm 0,9$ \\
\hline Abr & $12,2 \pm 2,3$ & $11,6 \pm 1,1$ & $-0,1 \pm 0,3$ & $0,2 \pm 0,3$ & $10,3 \pm 1,8$ & $6,3 \pm 0,9$ & $2,0 \pm 0,4$ & $5,3 \pm 0,8$ \\
\hline Mai & $8,1 \pm 2,6$ & $8,6 \pm 2,9$ & $-0,5 \pm 0,6$ & $-0,6 \pm 0,6$ & $7,0 \pm 2,0$ & $5,1 \pm 1,9$ & $1,6 \pm 0,6$ & $3,5 \pm 0,7$ \\
\hline Jun & $6,9 \pm 1,6$ & $7,9 \pm 1,8$ & $-0,3 \pm 0,4$ & $-0,1 \pm 0,2$ & $5,8 \pm 1,0$ & $4,5 \pm 1,1$ & $1,4 \pm 0,3$ & $3,2 \pm 1,2$ \\
\hline Jul & $6,9 \pm 2,8$ & $7,3 \pm 1,8$ & $-0,3 \pm 0,5$ & $-0,2 \pm 0,6$ & $5,6 \pm 1,8$ & $4,7 \pm 1,2$ & $1,6 \pm 0,7$ & $4,1 \pm 1,2$ \\
\hline Ago & $9,2 \pm 1,9$ & $9,2 \pm 2,1$ & $-0,1 \pm 0,3$ & $-0,3 \pm 0,4$ & $7,0 \pm 1,4$ & $5,2 \pm 1,3$ & $2,3 \pm 0,6$ & $4,1 \pm 1,2$ \\
\hline Set & $7,3 \pm 2,6$ & $8,7 \pm 2,4$ & $0,2 \pm 0,2$ & $0,2 \pm 0,3$ & $5,3 \pm 1,8$ & $6,0 \pm 1,8$ & $1,9 \pm 0,9$ & $2,7 \pm 1,2$ \\
\hline Out & $9,8 \pm 4,3$ & $10,1 \pm 4,7$ & $0,1 \pm 0,2$ & $0,4 \pm 0,5$ & $7,8 \pm 3,3$ & $5,7 \pm 2,7$ & $1,9 \pm 0,9$ & $3,9 \pm 1,6$ \\
\hline Nov & $11,2 \pm 4,2$ & $11,9 \pm 4,1$ & $0,0 \pm 0,2$ & $0,1 \pm 0,4$ & $9,2 \pm 3,3$ & $6,6 \pm 2,3$ & $2,1 \pm 0,8$ & $5,3 \pm 1,7$ \\
\hline Dez & $12,2 \pm 3,5$ & $13,2 \pm 3,1$ & $0,0 \pm 0,1$ & $0,0 \pm 0,2$ & $10,1 \pm 2,6$ & $7,8 \pm 1,8$ & $2,2 \pm 0,7$ & $5,5 \pm 1,2$ \\
\hline Churosa & $12,0 \pm 3,9$ & $12,0 \pm 3,6$ & $0,1 \pm 0,2$ & $-0,1 \pm 1,2$ & $9,8 \pm 3,1$ & $6,6 \pm 2,1$ & $2,1 \pm 0,7$ & $5,3 \pm 1,6$ \\
\hline Seca & $7,7 \pm 2,5$ & $8,4 \pm 2,5$ & $-0,2 \pm 0,5$ & $-0,2 \pm 0,5$ & $6,1 \pm 1,8$ & $5,1 \pm 1,6$ & $1,8 \pm 0,7$ & $3,7 \pm 1,2$ \\
\hline
\end{tabular}


O H no cambarazal apresentou um incremento de $16,7 \%$ (Tabela 1) da estação seca para a chuvosa, e na pastagem foi de $43,2 \%$ (Tabela 1). A menor variação estacional nos valores de $\mathrm{H}$ no cambarazal foi devido ao efeito liberador/moderador do armazenamento de energia da biomassa, o qual age no sentido de manter a baixa troca de calor entre a vegetação e a atmosfera durante todo o ano (Galvão e Fisch, 2000).

Os valores de $\mathrm{H}$ nos dois sítios apresentaram sazonalidade inversa às florestas e pastagens na região Amazônica, com maior média na estação chuvosa e menor na seca. No cambarazal, as médias mensais do $\mathrm{H}$ foram maiores que em floresta Amazônica na estação chuvosa $\left(2,0 \mathrm{MJ} \mathrm{m}^{-2}\right.$ dia $\left.^{-1}\right)$ e menores na estação seca (2,5 MJ m${ }^{-2}$ dia $\left.^{-1}\right)$ (Nobre et al., 1996; Galvão e Fisch, 2000). Além disso, foi maior que em floresta de transição Amazônia-Cerrado, 1,1 $\mathrm{MJ} \mathrm{m}^{-2} \mathrm{dia}^{-1}$ na estação chuvosa e $1,0 \mathrm{MJ} \mathrm{m}^{-2}$ dia $^{-1}$ na estação seca (Priante Filho et al., 2004). $\mathrm{Na}$ pastagem, as médias mensais de $\mathrm{H}$ foram maiores que em pastagens na estação chuvosa $\left(1,6-2,3 \mathrm{MJ} \mathrm{m}^{-2} \mathrm{dia}^{-1}\right)$ e menores na seca (4,4-5,1 MJ m ${ }^{-2}$ dia $^{-1}$ ) (Galvão e Fisch, 2000; Priante Filho et al., 2004).

O fluxo de calor no solo (G) foi o componente que apresentou menor variação sazonal (Tabela 1). No cambarazal, os valores positivos na estação chuvosa, indicam que neste período houve uma liberação de energia das camadas inferiores do solo para a superfície. Padrão inverso ocorreu na estação seca no cambarazal e nas estações seca e chuvosa na pastagem, indicando que a transmissão de calor da superfície para as camadas inferiores foi maior que a liberação de calor.

\subsection{Distribuição proporcional da energia disponível}

A fração da radiação solar incidente $(\mathrm{Rg})$ transformada em energia disponível (saldo de radiação - Rn) diminuiu da estação chuvosa para a seca (Tabela 2). Esta fração foi maior

Tabela 2 - Média mensal e estacional da partição da radiação solar incidente em saldo de radiação (Rn/Rg) e da partição do saldo de radiação em fluxo de calor no solo (G/Rn), fluxo de calor latente ( $\mathrm{LE} / \mathrm{Rn}$ ) e fluxo de calor sensível (H/Rn) no cambarazal (Camb.) e na pastagem (Past.).

\begin{tabular}{|c|c|c|c|c|c|c|c|c|}
\hline \multirow{2}{*}{$\begin{array}{c}\text { Més/ } \\
\text { Estaçäo }\end{array}$} & \multicolumn{2}{|c|}{$R n / R g$} & \multicolumn{2}{|c|}{$G / R n$} & \multicolumn{2}{|c|}{$L E / R n$} & \multicolumn{2}{|c|}{$H / R n$} \\
\hline & Camb. & Past. & Camb. & Past. & Camb. & Past. & Camb. & Past. \\
\hline Jan & 93,6 & & 0,7 & & 82,1 & & 17,2 & \\
\hline Fev & 92,4 & 94,8 & 0,3 & 6,5 & 81,4 & 48,6 & 18,3 & 44,9 \\
\hline Mar & 92,2 & 96,0 & 0,3 & 6,3 & 81,9 & 50,7 & 17,8 & 43,0 \\
\hline Abr & 87,0 & 87,9 & $-0,1$ & 6,5 & 83,8 & 54,5 & 16,3 & 39,0 \\
\hline Mai & 71,5 & 76,4 & $-0,5$ & 4,7 & 85,2 & 59,8 & 15,3 & 35,5 \\
\hline Jun & 59,8 & 69,7 & 3,9 & 6,5 & 83,0 & 56,8 & 13,1 & 36,7 \\
\hline Jul & 60,4 & 67,3 & 3,1 & 7,2 & 79,3 & 59,4 & 17,6 & 33,4 \\
\hline Ago & 59,8 & 66,8 & 2,3 & 7,8 & 76,0 & 56,5 & 21,7 & 35,7 \\
\hline Set & 57,5 & 69,1 & 2,9 & 9,5 & 72,1 & 68,3 & 25,0 & 22,2 \\
\hline Out & 70,9 & 85,6 & 2,5 & 7,5 & 78,8 & 56,2 & 18,7 & 36,3 \\
\hline Nov & 78,1 & 93,8 & 1,8 & 6,4 & 81,2 & 55,1 & 17,0 & 38,5 \\
\hline Dez & 79,5 & 94,1 & 1,9 & 5,4 & 81,8 & 58,8 & 16,3 & 35,8 \\
\hline Chuvosa & 84,0 & 91,4 & 0,9 & 6,7 & 81,6 & 54,8 & 17,5 & 38,5 \\
\hline Seca & 61,4 & 69,6 & 2,2 & 7,2 & 79,0 & 60,4 & 18,8 & 32,4 \\
\hline Seca s/ & & & & & & & & \\
\hline Setembro & 61,4 & 69,8 & 2,2 & 6,6 & 79,0 & 58,4 & 18,8 & 35,0 \\
\hline
\end{tabular}


na pastagem que no cambarazal, demonstrando que 8,6 e 16,0\% durante a estação chuvosa e 30,4 e $28,6 \%$ durante a estação seca da radiação solar foi perdida por reflexão e emissão pela pastagem e pelo cambarazal, respectivamente. Esses resultados concordam com Bastable et al. (1993) na região Amazônica, que 30 e $21 \%$ da energia radiante foi perdida na pastagem e na floresta, respectivamente.

A variação anual na relação $\mathrm{Rn} / \mathrm{Rg}$ também foi observada em gramado, variando de $59 \%$ em fevereiro a $47 \%$ em maio, tendo como principais causas dessa variação sazonal, o maior coeficiente de reflexão da superfície gramada no período seco, além da nebulosidade e umidade do ar associados ao regime de chuvas (Sentelhas e Nascimento, 2003). Segundo esses autores, o balanço de ondas é influenciado por essas variáveis, havendo redução da perda de radiação na faixa de infravermelho termal sob condições de alta umidade do ar e com presença de nuvens, o que resulta em maior saldo de radiação diário, aumentando a relação $\mathrm{Rn} / \mathrm{Rg}$, como o ocorrido nos meses da estação chuvosa.

Em geral, ambos os sítios destinaram a maior porcentagem da energia disponível $(\mathrm{Rn})$ à densidade de fluxo de calor latente (LE), $80,0 \%$ e 56,6\%, que à densidade de fluxo de calor sensível (H), 19,7\% e 36,2\%, e à densidade de fluxo de calor no solo $(\mathrm{G})$, $0,3 \%$ e $7,2 \%$ no cambarazal e na pastagem, respectivamente, durante todo o período de estudo.

Na estação chuvosa, a fração de Rn em LE foi de 81,6\% no cambarazal, enquanto que a pastagem foi $54,8 \%$ e na estação seca, essa relação foi de 79,0\% no cambarazal e $60,4 \%$ na pastagem (Tabela 2). O aumento da relação LE/Rn na pastagem foi devido ao aumento da umidade do solo, provocado pelo rompimento da tubulação da irrigação de uma área vizinha à área experimental na estação seca. Entre o final de agosto e meados de setembro de 2007, observou-se depósito d'água na pastagem, contribuindo para o aumento da disponibilidade de
Rn em LE (Tabela 2). Ao retirar o mês de setembro da relação $\mathrm{LE} / \mathrm{Rn}$, esta diminui para 58,4\%. A amplitude mensal desta relação no cambarazal foi $18,2 \%$, enquanto que na pastagem foi $40,5 \%$, demonstrando que o fluxo de calor latente na pastagem foi mais susceptível à variação da umidade do solo.

A fração de Rn destinada ao $\mathrm{H}$ no cambarazal foi menor na estação chuvosa, com incremento de $7,4 \%$ para a estação seca (Tabela 2). Na pastagem, incluindo o mês de setembro, essa fração diminuiu em 15,8\%. Mesmo excluindo o intervalo em que houve depósito de água no solo, a relação $\mathrm{H} / \mathrm{Rn}$ diminuiu 9,1\%, discordando de trabalhos como Bastable et al. (1993) e Priante Filho et al. (2004) em floresta Amazônica e transição Amazônica-Cerrado, respectivamente, os quais verificaram aumento de $\mathrm{H}$ na estação seca.

A fração de $\mathrm{Rn}$ destinada ao fluxo de calor no solo $(\mathrm{G})$, demonstrou que $\mathrm{G}$ foi o menor componente do balanço de energia nos dois sítios experimentais. No cambarazal a relação $\mathrm{G} / \mathrm{Rn}$ apresentou incremento de $244,4 \%$ da estação chuvosa para a seca (Tabela 2). Isso ocorreu devido à presença de lâmina d'água que impediu a transferência de calor da atmosfera para o solo e vice versa de janeiro a maio. A partir de junho, o valor desta fração aumentou na ausência de lâmina d'água, diminuindo até o final de dezembro. Na pastagem, G/Rn apresentou incremento de 7,4\% da estação chuvosa para a seca, entretanto, ao desconsiderar o mês de setembro, houve decréscimo de 1,5\% (Tabela 2).

Resultados de vários estudos indicam que a umidade do solo, potencial hídrico foliar e índice de área foliar em floresta, cerrado e pastagem diminuem durante a estação seca (McWilliam et al., 1996; Roberts et al., 1996; Sá et al., 1996; Meinzer et al., 1999). A queda na quantidade de água disponível e do índice de área foliar pode reforçar o aquecimento da superfície, provocar aumento no fluxo de calor sensível e conseqüentemente diminuição no fluxo de calor latente (Bastable et al., 1993).
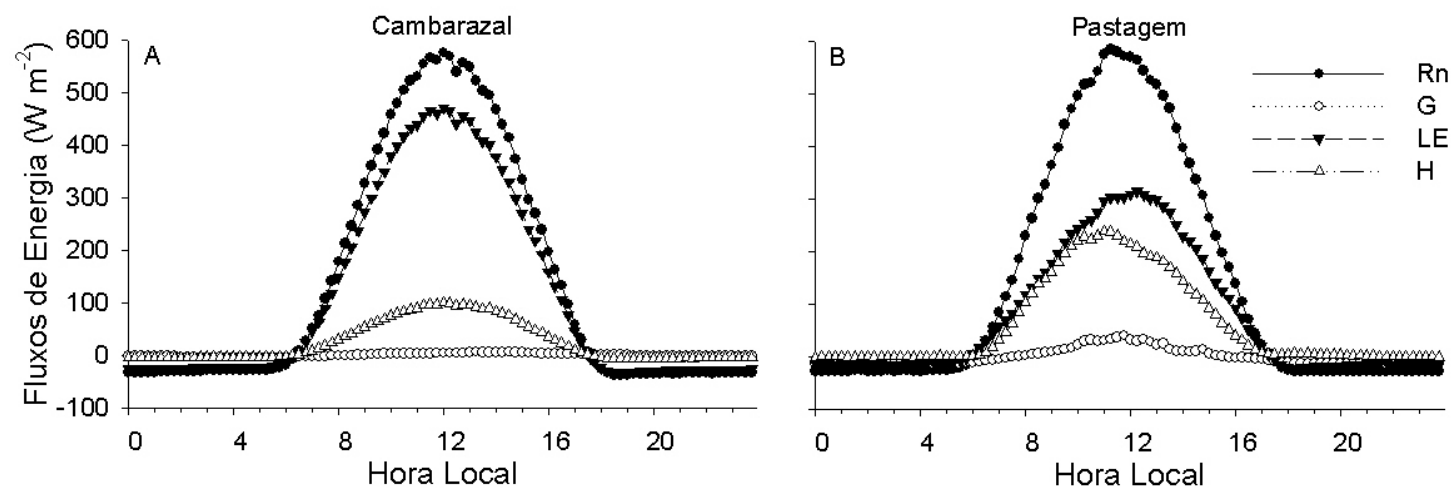

Figura 1 - Ciclo médio diário do saldo de radiação (Rn), fluxo de calor no solo (G), fluxo de calor latente (LE) e fluxo de calor sensível (H) no cambarazal e na pastagem, durante a estação chuvosa. 

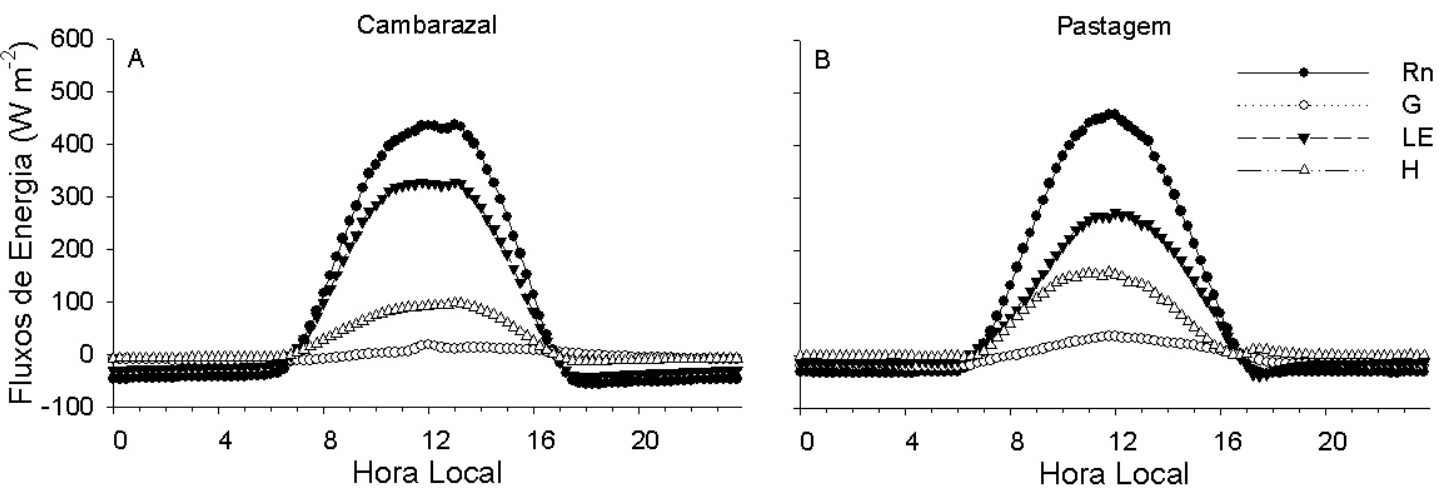

FIGURA 2 - Ciclo médio diário do saldo de radiação (Rn), fluxo de calor no solo (G), fluxo de calor latente (LE) e fluxo de calor sensível (H) no cambarazal e na pastagem, durante a estação seca.

Os valores médios de LE/Rn e H/Rn no cambarazal foram similares aos obtidos na floresta Amazônica (Shuttleworth, 1988; Roberts et al., 1993), em floresta de transição (Vourlitis et al., 2002; Priante Filho et al., 2004) e na pastagem (Wright et al., 1992; Bastable et al., 1993).

Simulações da altura da camada limite de florestas e pastagens na região Amazônica, sugerem que o desenvolvimento da pastagem altera a altura da camada limite noturna (Nobre et al., 1996), o que provoca diminuição de LE e aumento de $\mathrm{H}$ (Manzi e Planton, 1996). Além disso, provoca uma complexa mudança no padrão de circulação local e regional, podendo reduzir a precipitação e evaporação (20 a $30 \%$ ), aumentar a temperatura do ar $\left(\right.$ de 0,6 a $\left.2,0^{\circ} \mathrm{C}\right)$ e ainda aumentar a duração da estação seca, dependendo da vegetação local e da topografia (Dias e Regnier, 1996). A comparação do balanço de energia das duas áreas de estudo, com distinta cobertura vegetal, mas que apresentam características climáticas similares, não sugere que houve mudança na circulação local e regional, como estudos de Wright et al. (1992), Bastable et al. (1993) e Nobre et al. (1996).

Os maiores valores da relação $\mathrm{G} / \mathrm{Rn}$ na pastagem em relação ao cambarazal (Tabela 2), sugerem que este termo foi mais importante na pastagem que no cambarazal (Bastable et al., 1993; Priante Filho et al., 2004).

\subsection{Ciclo diário estacional dos componentes do balanço de energia}

Os valores dos ciclos médios estacionais dos fluxos apresentaram aumento a partir das primeiras horas do dia, atingindo máximos aproximadamente 12:00 h, seguido por um decréscimo até o final da tarde (Figuras 1 e 2). O Rn foi maior na estação chuvosa, atingindo máximo de 573,2 e $586,0 \mathrm{~W} \mathrm{~m}^{-2}$ no cambarazal e na pastagem (Figura 1), e na estação seca os máximos foram $573,2 \mathrm{~W} \mathrm{~m}^{-2}$ e $574,6 \mathrm{~W} \mathrm{~m}^{-2}$ no cambarazal e na pastagem (Figura 2), respectivamente.

A energia disponível aos dois ambientes foi convertida prioritariamente ao LE, apresentando maiores valores na estação chuvosa, 503,4 e $319,7 \mathrm{~W} \mathrm{~m}^{-2}$, e na seca foi $356,5 \mathrm{~W} \mathrm{~m}^{-2}$ no cambarazal e $259,7 \mathrm{~W} \mathrm{~m}^{-2}$ na pastagem, respectivamente. A diferença dos máximos na estação chuvosa está relacionada à maior disponibilidade hídrica no cambarazal devido à formação de lâmina d'água, que permaneceu entre janeiro e maio. A presença de água na superfície pode modificar o comportamento dos componentes do balanço de energia, por modificar as características físicas da superfície (Oliveira et al., 2006).

$\mathrm{O} \mathrm{H}$ foi maior na pastagem, atingindo $239,4 \mathrm{~W} \mathrm{~m}^{-2}$ na estação chuvosa e $159,3 \mathrm{~W} \mathrm{~m}^{-2}$ na estação seca. No cambarazal, o $\mathrm{H}$ atingiu $100,3 \mathrm{~W} \mathrm{~m}^{-2}$ na estação chuvosa e $97,9 \mathrm{~W} \mathrm{~m}^{-2}$ na estação seca. Essa diferença se deve à maior biomassa no cambarazal, a qual regula as trocas de energia entre a superfície vegetada e a atmosfera (Galvão e Fisch, 2000).

$O \mathrm{G}$ foi cerca de quatro vezes maior na pastagem, na estação chuvosa $\left(\mathrm{Gmax}=41,4 \mathrm{~W} \mathrm{~m}^{-2}\right)$ e duas vezes maior na estação seca $\left(\mathrm{Gmax}=37,6 \mathrm{~W} \mathrm{~m}^{-2}\right)$ que no cambarazal, na estação chuvosa $\left(\mathrm{Gmax}=6,9 \mathrm{~W} \mathrm{~m}^{-2}\right)$ e na seca $\left(\mathrm{Gmax}=18,4 \mathrm{~W} \mathrm{~m}^{-2}\right)$, respectivamente. Os menores valores de $\mathrm{G}$ no cambarazal na estação chuvosa foram devido à influência da lâmina d'água ocorrida entre janeiro e maio.

\section{CONCLUSÕES}

Os componentes do balanço de energia apresentaram sazonalidade, com maiores médias observadas na estação chuvosa nas duas áreas.

O fluxo de calor latente foi maior no cambarazal e os fluxos de calor sensível e no solo foram maiores na pastagem durante todo o ano. 
O saldo de radiação foi destinado prioritariamente ao fluxo de calor latente, cuja relação foi de $80,0 \%$ no cambarazal e $56,6 \%$ na pastagem, seguido pelo fluxo de calor sensível, 19,1 e $42,9 \%$, e pelo fluxo de calor no solo, 0,3 e 7,2\%, respectivamente.

\section{REFERÊNCIAS BIBLIOGRÁFICAS}

ARRUDA, J.C.; JORGE, A.; PRIANTE FILHO, N.; NOGUEIRA, J.S.; ALMEIDA FILHO, E.O.; CAMPELO JÚNIOR, J.H.C.; VOURLITIS, G.L. Aplicação de três metodologias para estimar o fluxo de calor latente em floresta de transição. Revista Brasileira de Meteorologia, v. 21, n. 3b, p. 233-240, 2006.

ARTAXO, P.; MARTINS, J.V.; YAMASOE, M.A.; PROCÓPIO, A.S.; PAULIQUEVIS, T.M.; ANDREAE, M.O.; GUYON, P.; GATTI, L.V.; CORDOVA, A.M. Physical and chemical properties of aerosols in the wet and dry season in Rondônia, Amazônia. Journal of Geophysical Research, v. 107, n. D20, p. 8081-8095, 2002.

BASTABLE, H.G.; SHUTTLEWORTH, W.J.; DALLAROSA, R.L.G.; FISCH, G.; NOBRE, C.A. Observations of climate, albedo and surface radiation over cleared and undisturbed Amazonian Forest. International Journal of Climatology, v. 13, p. 783-796, 1993.

DIAS, M.A.F.S.; REGNIER, P. Simulation of mesoscale circulations in a deforested area of Rondônia in the dry season. In: GASH, J.H.C.; NOBRE, C.A.; ROBERTS, J.M.; VICTORIA, R.L. (Eds.) Amazonian Deforestation and Climate. New York: J. M. Wiley and Sons, 1996, p. 531-547.

GALVÃO, J.A.C.; FISCH, G. Balanço de energia em áreas de floresta e de pastagem na Amazônia (Ji-Paraná, RO). Revista Brasileira de Meteorologia, v. 15, n. 2, p. 25-37, 2000.

JARVIS, P.G.; JAMES, G.B.; LANDSBERG, J.J. Coniferous forests. In: MONTEITH, J.L. (Ed.) Vegetation and the Atmosphere: Case Studies. London: Academy Press, v. 2, p. 171-240, 1976.

JUNK W.J. Long-term environmental trends and the future of tropical wetlands. Environmental Conservation, v. 29, n. 4, p. 414-435, 2002.

LIMA, J.R.S.; ANTONINO, A.C.D.; LIRA, C.A.B.O.; SILVA, I.F. Estimativa da evapotranspiração em uma cultura de feijão caupi, nas condições de brejo Paraibano. Agropecuária Técnica, v. 26, n. 2, p. 86-92, 2005.

LIU, H.; FOKEN, T. A modified Bowen ratio method to determine sensible and latent heat fluxes. Meteorologische Zeitschrift, v. 10, n. 1, p. 71-80, 2001.

MANZI, A.O.; PLANTON, S. A simulation of Amazon deforestation using a GCM calibrated with ABRACOS and
ARME data. In: GASH, J.H.C.; NOBRE, C.A.; ROBERTS, J.M.; VICTORIA, R.L. (Eds.) Amazonian Deforestation and Climate. New York: J. M. Wiley and Sons, 1996, p. 505-529.

McWILLIAM, A.L.C.; CABRAL, O.M.R.; GOMES, B.M.; ESTEVES, J.L.; ROBERTS, J.M. Forest and pasture leaf gas exchange in southwest Amazonia. In: GASH, J.H.C.; NOBRE, C.A.; ROBERTS, J.M.; VICTORIA, R.L. (Eds.) Amazonian Deforestation and Climate. New York: J. M. Wiley and Sons, 1996, p. 265-286.

MEINZER, F.C.; GOLDSTEIN, G.; FRANCO, A.C.; BUSTAMANTE, M.; IGLER, E.; JACKSON, P.; CALDAS, L.; RUNDEL, P.W. Atmospheric and hydraulic limitations on transpiration in Brazilian Cerrado woody species. Functional Ecology, v. 13, p. 273-282, 1999.

NOBRE, C.A.; FISCH, G., ROCHA, H.R.; LYRA, R.F.F.; ROCHA, E.P.; COSTA, A.C.L.; UBARANA, V.N. Observations of the atmospheric boundary layer in Rondônia. In: GASH, J.H.C.; NOBRE, C.A.; ROBERTS, J.M.; VICTORIA, R.L. (Eds.) Amazonian Deforestation and Climate. New York: J. M. Wiley and Sons, 1996, p. 413-424.

NUNES da CUNHA, C.; JUNK, W.J. Year-to-year changes in water lavel drive the invasion of Vochysia divergens in Pantanal glassland. Applied Vegetation Science, v. 7, p. 103-110, 2004.

OLIVEIRA, M.B.L.; VON RANDOW, C.; MANZI, A.O.; ALVALÁ, R.C.; SÁ, L. D.; LEITÃO, M.M.V.B.R.; SOUZA, A. Fluxos turbulentos de energia sobre o Pantanal sul matogrossense. Revista Brasileira de Meteorologia, v. 21, n. 3b, p. 159-165, 2006.

ORTEGA FARIAS, S.O.; CUENCA, R.H.; EK, M. Daytime variation of sensible heat flux estimated by the bulk aerodynamic method over a grass canopy. Agricultural and Forest Meteorology, v. 81, p. 131-143, 1996.

PEZZOPANE, J.R.M.; PEDRO JÚNIOR, M.J. Balanço de energia em vinhedo de 'Niagara Rosada'. Bragantia, v. 62, n. 1, p. 155-161, 2003.

PRIANTE FILHO, N.; VOURLITIS, G.L.; HAYASHI, M.M.S.; NOGUEIRA, J.S.; CAMPELO JÚNIOR, J.H.; NUNES, P.C.; SOUZA, L.S.; COUTO, E.G.; HOEGER, W.; RAITER, F.; TRIENWEILER, J.L.; MIRANDA, E.J.; PRIANTE, P.C.; FRITZEN, C.L.; LACERDA, M.; PEREIRA, L.C.; BIUDES, M.S.; SULI, G.S.; SHIRAIWA, S.; PAULO, S.R.; SILVEIRA, M. Comparison of the mass and energy exchange of a pasture and a mature transitional tropical forest of the southern Amazon Basin durin a seasonal transition. Global Change Biology, v. 10, p. 863-876, 2004.

ROBERTS, J.; CABRAL, O.M.R.; FISCH, G.; MOLION, L.C.B.; MOORE C.J.; SHUTTLEWORTH, W.J. Transpiration 
from an Amazonian rainforest calculated from stomatal conductance measurements. Agricultural and Forest Meteorology, v. 65, p. 175-196, 1993.

ROBERTS, J.; CABRAL. O.M.R.; COSTA, J.P.; McWILLIAM, A.L.C.; SÁ, T. D.A. An overview of the leaf area index and physiological measurements during ABRACOS. In: GASH, J.H.C.; NOBRE, C.A.; ROBERTS, J.M.; VICTORIA, R.L. (Eds.) Amazonian Deforestation and Climate. New York: J. M. Wiley and Sons, 1996, p. 287-306.

SÁ, L.D.A.; VISWANADHAM, Y.; MANZI, A.O. Energy flux partitioning over the Amazon Forest. Theoretical and Applied Climatology, v. 39, p. 1-16, 1988.

SANTOS, S.A.; COSTA, C. Manejo sustentável das pastagens nativas: uma ação essencial para a implantação de um sistema orgânico de produção no Pantanal. In: Conferência Virtual Global sobre Produção Orgânica de Bovinos de Corte, I, 2002, Corumbá, Brasil. Anais... Corumbá: Embrapa Pantanal, 2002.

SENTELHAS, P.C.; NASCIMENTO, A.L.C. Variação sazonal da relação entre o saldo de radiação e a irradiância solar global. Revista Brasileira de Meteorologia, v. 18, n. 1, p. 71-77, 2003.
SILVA, L.D.B.; FOLEGATTI, M.V.; VILLA NOVA, N.A. Evapotranspiração do capim tanzânia obtida pelo método de razão de Bowen e lisímetro de pesagem. Engenharia Agrícola, v. 25, n. 3, p. 705-712, 2005.

SHUTTLEWORTH, W.J. Evaporation from Amazonian Rainforest. Proceedings of the Royal Society of London (Series B), v. 233, p. 321-346, 1988.

VOURLITIS, G.L.; PRIANTE-FILHO, N.; HAYASHI, M.M.S.; NOGUEIRA, J.S.; CASEIRO, F.T.; CAMPELO JÚNIOR, J.H. Seasonal variations in the evapotranspiration of a transitional tropical forest of Mato Grosso, Brasil. Water Resources Research, v. 38, p. 1-11, 2002.

WRIGTH，I.R.; GASH，J.H.C.; ROCHA，H.R.; SHUTTLEWORTH, W.J.; NOBRE, C.A.; MAITELLI, G.T.M.; ZAMPARONI, C.A.G.P.; CARVALHO, P.R.A. Dry season micrometeorology of Central Amazonian ranchland. Quartely Journal of Royal Meteorological Society, v. 118, n. 508, p. 1083-1099, 1992. 